\title{
EVENTOS GASTRONÔMICOS: UM ESTUDO DE CASO SOBRE O FESTIVAL DE QUEIJO COALHO DE JAGUARIBE-CEARÁ
}

\author{
Victor Hugo Santos de Castro ${ }^{1}$, Francisca da Silva FÉliX ${ }^{1}$ \\ ${ }^{1}$ Instituto Federal de Educação, Ciência e Tecnologia do Ceará - IFCE \\ <vsantosdecastro@yahoo.com.br><xica.da.silva.051@hotmail.com>
}

DOI: $10.21439 /$ conexoes.v15i0.1253

\begin{abstract}
Resumo. O estudo aborda o Festival do Queijo Coalho em Jaguaribe-Ceará, também conhecido como Quejaribe. A pesquisa teve como objetivo geral: analisar os impactos em um meio de hospedagem e na economia local através da realização do evento. Teve como objetivos específicos: comparar a taxa de ocupação do meio de hospedagem no período do festival com as demais épocas do ano; identificar as estratégias de hospitalidade utilizadas pelo empreendimento hoteleiro; verificar a visão econômica do gestor do meio de hospedagem, quanto aos impactos do evento gastronômico na localidade. A metodologia utilizada foi de caráter exploratório, com uma abordagem qualitativa. O instrumento de coleta de dados utilizado foi a entrevista semiestruturada, aplicada a um meio de hospedagem e à Associação dos Produtores de Leite da região. A entrevista foi gravada e a análise dos dados ocorreu por meio da transcrição das falas dos entrevistados. Os resultados apontam que o evento eleva a taxa de ocupação do meio de hospedagem, contribuindo também para a economia, pois as vendas do comércio local aumentam, atraindo mais negócios. O estudo concluiu que o Festival Queijaribe traz mais visitantes e que a hotelaria local é beneficiada com a realização deste evento, apesar da inexistência de uma divulgação integrada entre os empreendimentos hoteleiros e a organização do evento.
\end{abstract}

Palavras-chaves: Eventos Gastronômicos. Festival do Queijo Coalho. Queijaribe. Jaguaribe-Ceará.

\section{GASTRONOMIC EVENTS: A CASE STUDY OF THE CURD CHEESE FESTIVAL IN JAGUARIBE-CEARÁ}

\begin{abstract}
The study deals with the Festival do Queijo Coalho in Jaguaribe-Ceará, also known as Quejaribe. The research had as general objective: to analyze the impacts in a lodging environment and in the local economy through the accomplishment of the event. It had specific objectives: to compare the occupation rate of the lodging medium in the period of the festival with the other times of the year; identify the hospitality strategies used by the hotel development; verify the economic vision of the manager of the lodging environment, as to the impacts of the gastronomic event in the locality. The methodology used was exploratory, with a qualitative approach. The data collection instrument used was the semistructured interview, applied to a lodging medium and the Associação dos Produtores de Leite of the region. The interview was recorded and the analysis of the data occurred through the transcription of the interviewees' statements. The results indicate that the event raises the occupancy rate of the lodging environment, also contributing to the economy, as it increases sales of local commerce, attracting more business. The study concluded that the Queijaribe Festival brings more visitors and that the local hotel industry is benefited by the realization of this event, despite the inexistence of an integrated dissemination between the hotel developments and the organization of the event.
\end{abstract}

Keywords: Gastronomic Events. Festival do Queijo Coalho. Queijaribe. Jaguaribe-Ceará. 


\section{INTRODUÇÃO}

Evento é um acontecimento, que reúne pessoas, em determinado local, com data e hora pré-definidos. Os objetivos dos eventos estão relacionados ao seu tipo e público-alvo, podem ser destinados a vendas em geral, degustação, exposição, oficinas, orientações, premiações e outros.

Bahl (2004), afirma que os eventos podem acontecer por diferentes motivos e que se faz necessário planejar de acordo com o público-alvo, objetivo, local de realização, dia, data, horário e outros recursos necessários para a concretização do acontecimento.

Entre os vários tipos de eventos, destacam-se os gastronômicos, afinal, cada região tem sua gastronomia própria, e assim surgem os festivais de comida típica de cada Estado. Estes festivais, podem incentivar o deslocamento de pessoas, contribuindo para o desenvolvimento do turismo em determinada localidade.

A culinária desperta a curiosidade das pessoas, não só na sua parte visual e de degustação, mas também em aprofundar o conhecimento na área. Desperta-se o interesse em conhecer os profissionais que fazem o preparo do alimento, além da cultura e origem da preparação da comida (OLIVEIRA, 2007).

Alguns municípios implementam festas gastronômicas em seu calendário de atividades, com o objetivo de provocar o deslocamento de mais visitantes, para explorar a comida da região. O público destes eventos tem o propósito de compartilhar vivências, opiniões, conhecimentos da área. A divulgação destes eventos ocorre através da mídia e relações sociais (TENAN, 2002).

Jaguaribe, cidade localizada no Estado do Ceará, está inserida na rota de turismo da região do Vale de Jaguaribe e tem como atrativos turísticos: a barragem de Santana, a estátua de Nossa Senhora das Candeias às margens do rio Jaguaribe e a Praça Juarez Távora. Quanto à culinária local destacam-se os pratos típicos como: baião de dois, cuscuz, tapioca, carne de bode, buchada, panelada, galinha caipira, peixe frito, pirão, macaxeira, arroz de leite, bolo de milho, doce de elite, manteiga de garrafa, mel de engenho, rapadura, sobretudo o queijo coalho.

O município realiza o Festival de Queijo Coalho, também denominado Queijaribe. Este evento é realizado no Parque de Exposição do referido município, e tem como objetivo promover e comercializar o queijo coalho produzido na região, assim como qualificar o participante no que tange ao preparo e conservação do queijo. Portanto, o problema dessa pesquisa foi: quais os impactos do Festival do Queijo Coalho para os meios de hospedagem e para a economia da cidade de Jaguaribe?
O objetivo geral do estudo foi analisar os impactos do Festival do Queijo Coalho para um meio de hospedagem e na economia da cidade em questão. Os objetivos específicos foram: comparar a taxa de ocupação do meio de hospedagem no período do festival com as demais épocas do ano; identificar as estratégias de hospitalidade utilizadas pelo meio de hospedagem; verificar a visão econômica do gestor do meio de hospedagem, quanto aos impactos do evento gastronômico na localidade.

Quanto à metodologia, tratou-se de uma pesquisa de campo, com uma abordagem qualitativa, cujo instrumento de coleta de dados foi a entrevista semiestruturada. A entrevista foi aplicada a uma pousada e à Associação dos Produtores de Leite. A análise dos dados foi realizada através da transcrição das falas dos entrevistados.

A relevância deste estudo consiste na sistematização dos impactos do evento gastronômico para a taxa de ocupação de um meio de hospedagem e na economia local. Esta pesquisa é importante também para os profissionais de eventos, gastronomia, hotelaria e turismo.

Este estudo apresenta seções sobre a culinária, a gastronomia e o turismo gastronômico; a metodologia para a obtenção dos dados; a discussão dos resultados obtidos; e as considerações sobre a pesquisa.

\section{FUNDAMENTAÇÃO}

\subsection{Culinária e Gastronomia}

A gastronomia brasileira, ao longo do tempo, vem inovando e agregando mais temperos e elementos de outras cozinhas, como a francesa e a italiana para aprimorar seus pratos. A gastronomia é o referencial da cultura de um povo. A culinária dá prazer não só para quem vai saborear o prato, mas também para quem o faz, pois, cada pessoa tem sua própria maneira de preparar (AZEVEDO, 2010).

\footnotetext{
Através da alimentação, é possível visualizar e sentir tradições que não são ditas. A alimentação é também memória, opera muito fortemente no imaginário de cada pessoa, e está associada aos sentidos: odor, visão, o sabor e até a audição. Destaca as diferenças, as semelhanças, as crenças e a classe social a que pertence, por carregar as marcas da cultura (BARROCO 2008 p. 4).
}

Os profissionais de área gastronômica devem observar a textura, a aparência, a cor, o sabor e o visual do alimento. São responsáveis ainda por verificar a procedência dos produtos. Durante o preparo deve-se manter as propriedades nutricionais para quem irá consumir.

Gastronomia é uma disciplina que exige arte não somente de quem executa, mas também de quem a consome ou usufrui. É artesanato, porque exige de quem 
a faz conhecimento, habilidade e técnica. É uma arte ou ciência que exige conhecimento e técnica de quem a executa e formação do paladar de quem a aprecia (BRAUNE; FRANCO 2007 p. 14)

Os profissionais que trabalham no manuseio do alimento precisam usar toucas no cabelo, as unhas devem estar bem cortas, o uniforme sempre limpo. O profissional que irá servir deve estar sempre com um sorriso, ser amável, acolher o cliente da melhor forma possível (MONTANARI, 2008).

Ginani (2005) afirma que as técnicas usadas para preparar os alimentos variam muito de um lugar para outro, uma vez que existem temperos da própria região e métodos específicos de cocção. Os temperos dão sabor e aroma aos pratos, os mais conhecidos são: orégano, manjericão, alecrim, açafrão, entre outros, presentes em várias culturas. As possibilidades de harmonia destes temperos com os pratos são inúmeras e sua utilização dependerá da criatividade do cozinheiro.

Existem restaurantes que oferecem serviços de motorista para os clientes, cardápios disponibilizados via aplicativos de celulares, com opções de fazer o pedido, sem precisar de um garçom. Alguns disponibilizam ainda entretenimento no ambiente, como shows de humor, música ao vivo com artistas da região (OLIVEIRA, 2000).

Os estabelecimentos de restauração estão sempre buscando atender às necessidades dos clientes, inovando nos pratos, na recepção do comensal, na infraestrutura do local, com serviços mais práticos, rápidos e de qualidade, a fim de atrair e fidelizar seu público.

\subsection{Turismo Gastronômico e o Festival do Queijo Coalho de Jaguaribe}

O Brasil é um país muito rico quanto à gastronomia, existe uma heterogeneidade de culturas, de tradições que a torna mais forte, vários ingredientes, temperos, aromas diferenciados fazem com que as pessoas visitem cidades para conhecer a gastronomia do local.

"Não é somente o ato de provar os pratos que atrai aos visitantes, mas também o fato de poder conhecer ritos e hábitos associados à gastronomia de um povo e a possibilidade de visitar museus e outras atrações com esta temática" (OLIVEIRA, 2007, p. 37).

Comer no seu tempo é saber escolher entre as incríveis propostas que a cidade nos oferece e os desejos agudos de um corpo que constantemente pede novas sensações. Por que comemos? Para nos sentirmos melhores, para estar bem, para ser bons. Para ter uma cabeça sempre desperta, uma acuidade permanente, um corpo feliz, uma alma bem acompanhada (SIMON. 2006 p. 60).

Cada estado ou cidade brasileira tem sua tradição gastronômica, com uma culinária rica e que aguça a curiosidade de todos em conhecê-la e degustá-la. As localidades possuem temperos específicos e diferentes modos de preparo (ANSARAH; NUNES, 2007).
Se a gastronomia pode ser ligada a um país específico ou regiões, ela se tornará uma ferramenta poderosa de marketing. A autenticidade sempre foi vista como um importante aspecto do consumo turístico, e procurando por autenticidade local e regional, a comida pode se tornar motivo para visitação em um destino em particular (RICHARDS 1999 p. 12).

A região Nordeste, destaca-se na gastronomia por ofertar ao turista: a cana-de-açúcar, o milho, a mandioca, o feijão e outros. Além dos pratos típicos como o baião de dois, arroz de leite, peixe assado, buchada, pirão e outros (CAMPOS et al., 2002).

Turismo e alimentação podem e devem caminhar lado a lado. Esse aproveitamento de elementos gastronômicos de diferentes localidades turísticas pode ser feito de forma vantajosa para todas as partes envolvidas: turistas, gestores, planejadores e comunidade. Ao mesmo tempo em que se trabalha a questão de valorização da cultura, por meio de valorização de culinárias tradicionais e da criação de novos empregos, também se disponibiliza oferta maior e diferenciada de atrativos turísticos para os visitantes (FAGLIARI 2005. p. 16).

Através da gastronomia as pessoas despertam o interesse em visitar e conhecer novas culinárias, identificando outras culturas através da gastronomia. Isto motiva uma viagem, visto que a alimentação é uma das necessidades do ser humano (SCHLUTER, 2003). A autora afirma ainda que "a gastronomia, sem dúvida, está ganhando terreno como atração tanto para residentes como para turistas. Não só nutre o corpo e o espírito, mas faz parte da cultura dos povos" (SCHLUTER. 2003 p. 89).

\footnotetext{
A gastronomia enquanto cultura, desperta curiosidades nas pessoas e, como o turismo, é mediadora para saciar as inúmeras curiosidades do turista, também, transmite ideia de status e classe social não apenas para o turista como para a população (CUNHA; OLIVEIRA 2009. p. 4).
}

Mitchell e Hall (2003) afirmam que o turismo gastronômico é alvo dos profissionais da área de alimentos e é motivado pela participação em festivais e eventos gastronômicos, vivências e experiências em restaurantes e outros elementos culturais.

O Turismo Gastronômico está relacionado à felicidade de sentir e degustar algo novo em uma viagem, tendo as expectativas atendidas. Algumas regiões possuem roteiros gastronômicos para que os visitantes vivenciem a cultura, a história e as tradições dos pratos típicos da região (SEGALA, 2003). 
O Turismo Gastronômico vem aumentando as possibilidades de trabalho em equipamentos de restauração, e, por conseguinte, avanços na economia local, uma vez que gera empregos diretos e indiretos e renda (CORNER; RODRIGUEZ, 2006).

O Festival de Queijo Coalho de Jaguaribe, teve sua $12^{\circ}$ edição, realizada em 2016. Este evento tem envolve conhecimentos sobre a culinária, seu preparo utilizando o queijo da região, potencializa a comercialização, contribuindo para o êxito gastronômico da localidade.

O evento atrai compradores, donas de casa, proprietários de restaurantes, dentre outros. Existe um concurso, do melhor queijo coalho, os três primeiros lugares são premiados. Ressalta-se que não há um levantamento de participantes presentes no evento. O mesmo surgiu de uma necessidade de potencializar o produto mais famoso da região, o queijo coalho.

Quanto aos queijos, estes podem ser de vários tipos de leite, vaca, cabra, ovelha, búfalo e outros. O queijo tem vários formatos como: redondo, quadrado, triangular. E podem ser também temperados de várias formas, doce ou salgado, apimentado (LÁCTEA BRASIL, 2006). O queijo de coalho é importante para os produtores e para a região, pois traz impactos positivos na economia, por gerar emprego e renda. Além disso, as principais queijarias ficam no Nordeste, produzindo um dos melhores queijos do país (PERRY, 2004).

\section{METODOLOGIA}

Tratou-se de um estudo de caso, de caráter exploratório, com abordagem qualitativa. Creswell (2010, p. 43) define a abordagem qualitativa como sendo "um meio para explorar e para entender o significado que os indivíduos ou os grupos atribuem a um problema social ou humano".

O cenário de pesquisa foi composto por um meio de hospedagem de Jaguaribe, sendo escolhido intencionalmente, e a Associação dos Produtores de Leite. Os participantes da pesquisa foram os gestores responsáveis pelos empreendimentos.

Associação dos Produtores de Leite foi alvo desta pesquisa por organizar o evento Queijaribe. A escolha do meio hospedagem se deu pela melhor infraestrutura ofertada ao turista. Trata-se de uma pousada que dispõe de estacionamento próprio, wifi, café da manhã, televisão de lcd, ar-condicionado e frigobar nos quartos, dentre outros serviços. Existem cinco pousadas e um hotel no município.

A coleta de dados foi realizada através de entrevistas semiestruturadas. A entrevista aplicada à Associação dos Produtores de Leite possuía três questões, já a entrevista aplicada à pousada foi composta por cinco perguntas. Foi realizado um agendamento prévio por telefone, para verificar a disponibilidade dos entrevistados. As entrevistas foram realizadas em maio de 2016. Foi informado que a entrevista seria gravada e que os participantes poderiam desistir a qualquer momento da participação na pesquisa. A análise dos dados foi realizada através da transcrição das falas dos participantes.

\section{RESULTADOS E DISCUSSÕES}

Nesta seção apresentam-se os resultados coletados através de entrevistas e respectivas discussões embasadas em resultados de pesquisadores da área em questão. A pesquisa foi realizada com o representante da Associação dos Produtores de Leite de Jaguaribe e o gestor de um meio de hospedagem, os mesmos responderam a seis perguntas na forma de entrevista.

A primeira pergunta da entrevista teve como objetivo avaliar a importância do Festival Queijaribe para a cidade de Jaguaribe, os resultados apontam o aumento do número de visitantes na cidade, como pode ser observado nas falas abaixo.

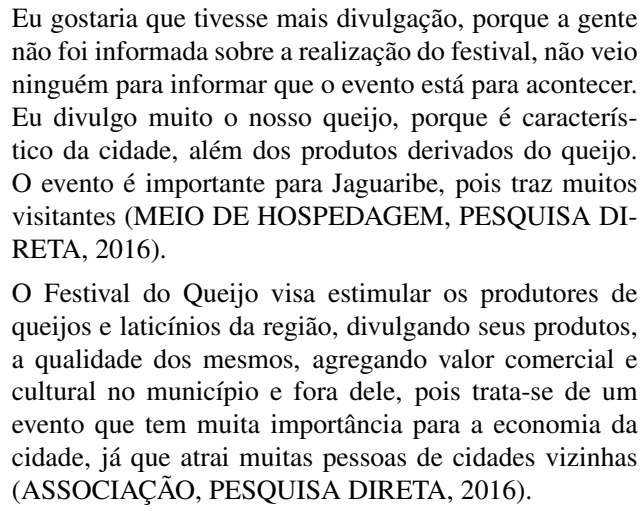

Eu gostaria que tivesse mais divulgação, porque a gente não foi informada sobre a realização do festival, não veio ninguém para informar que o evento está para acontecer. Eu divulgo muito o nosso queijo, porque é característico da cidade, além dos produtos derivados do queijo. $\mathrm{O}$ evento é importante para Jaguaribe, pois traz muitos visitantes (MEIO DE HOSPEDAGEM, PESQUISA DIRETA, 2016).

O Festival do Queijo visa estimular os produtores de queijos e laticínios da região, divulgando seus produtos, a qualidade dos mesmos, agregando valor comercial e cultural no município e fora dele, pois trata-se de um evento que tem muita importância para a economia da cidade, já que atrai muitas pessoas de cidades vizinhas (ASSOCIAÇÃO, PESQUISA DIRETA, 2016).

O Festival do Queijaribe, traz melhorias para a cidade, pois a divulgação do queijo é essencial para promover as vendas e gerar mais empregos, sejam formais ou informais. O evento é ainda uma possibilidade de aquisição de conhecimento através dos cursos e degustação, de entretenimento, através da competição do melhor queijo. Porém, a divulgação do festival é falha, pois não há uma comunicação efetiva entre a Associação responsável pelo evento e os meios de hospedagem da região.

Observa-se que o evento aumenta o número de visitantes na região, o que impacta diretamente na economia, já que mais pessoas estarão consumindo os produtos e serviços da cidade. Corroborando com tal assertiva, os eventos são significativos para ao turismo por elevar a economia e colaborar para o enriquecimento cultural, além de manter e propagar a identidade da localidade (AITKEN, 2002). 
No segundo questionamento procurou-se analisar os pontos positivos e negativos do festival para a região. Os positivos são as vendas para o comércio, o lazer e diversão para a população, e alguns empregos temporários. Os negativos são mais poluição, devido a produção de lixo nas ruas, e a pouca divulgação do evento, como pode ser observado nas falas a seguir.

\section{Desde que ele seja bem trabalhado, bem divulgado, com antecedência, em várias cidades, eu acredito que seja muito positivo para cidade. O festival é um momento de lazer para a comunidade, é diversão garantida. O ruim é que a cidade fica suja depois da realização do evento (MEIO DE HOSPEDAGEM, PESQUISA DI- RETA, 2016). \\ A agropecuária de uma maneira geral é a principal fonte de renda do nosso município, então, o impacto é econô- mico e financeiro, porque esta atividade sustenta boa parte das famílias, principalmente na zona rural, com a venda do leite, e produção de queijo e derivados. Com o evento, empregos temporários são gerados para a comu- nidade (ASSOCIAÇÃO, PESQUISA DIRETA, 2016).}

Quanto aos aspectos negativos, relacionados às causas ambientais, seria de fundamental importância que a Associação dos Produtores de Leite em consonância com a prefeitura de Jaguaribe, desenvolvessem estratégias para evitar o aumento de resíduos nas ruas da cidade. $\mathrm{O}$ terceiro questionamento abordou o impacto do evento na hotelaria da cidade. Obteve-se que a demanda desse evento é ideal, e os meios de hospedagem comportam o número de visitantes no período do acontecimento, como descrito na fala abaixo.

Os visitantes podem ser bem acomodados nas unidades habitacionais dos meios de hospedagem da região. Dependendo do ano, a taxa de ocupação pode chegar a $100 \%$, o que é excelente para os lucros. Os impactos das festividades da cidade são sempre positivos, com certeza, todos os empreendedores ficam satisfeitos (MEIO DE HOSPEDAGEM, PESQUISA DIRETA, 2016).

Quando a taxa de ocupação é máxima, o meio de hospedagem aumenta seus ganhos e pode aproveitar o momento para mostrar a excelência dos produtos e serviços do seu estabelecimento, garantindo a satisfação do cliente e possível fidelização.

A quarta pergunta buscou fazer um comparativo da taxa de ocupação do meio de hospedagem entre o período festivo e as demais épocas do ano. Foi constatado que tal taxa se eleva quando ocorre o festival e que em outros períodos a ocupação do meio de hospedagem é inferior.

Como afirmado anteriormente, a taxa de ocupação é máxima no período do festival, mas nos outros meses do ano, a taxa é menor. Sempre quando ocorre alguma festa na região, há uma tendência de aumentar o número de quartos ocupados no nosso empreendimento. Nossos serviços sempre são realizados com qualidade para o bem-estar do hóspede (MEIO DE HOSPEDAGEM, PESQUISA DIRETA, 2016).

Cobra e Rangel (1993, p. 43) afirmam que "satisfazer o consumidor implica descobrir necessidades, exigências, de forma a manter o cliente permanentemente interessado". O meio de hospedagem em questão, afirma que recebe bem os clientes, porém deve continuar investindo em técnicas de acolhimento, para que seus serviços sejam considerados excelentes e a divulgação seja feita através de referências de outros clientes, contribuindo assim para a taxa de ocupação em outros períodos.

Shiozawa (1993, p. 52) o atendimento é fundamental para que o cliente opte por determinado serviço ou produto, segundo o autor atendimento pode ser entendido como "todas as melhorias, benefícios e diferenciações, baseadas no profundo conhecimento do cliente, que ajudem a criar o serviço ou produto potencial".

A quinta pergunta buscou identificar como ocorre a divulgação do Queijaribe na cidade e região, ou seja, como ocorre a disseminação das informações nos meios de comunicação de massa e também nos meios de hospedagem, como resultado obteve-se que além de produzir panfletos, a associação utiliza as redes sociais e outros mecanismos de comunicação para atingir o público-alvo, como pode ser observado na fala a seguir.

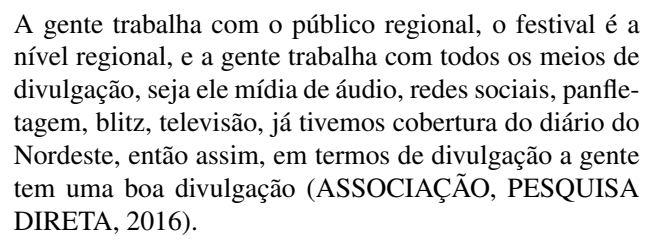
divulgação, seja ele mídia de áudio, redes sociais, panfletagem, blitz, televisão, já tivemos cobertura do diário do Nordeste, então assim, em termos de divulgação a gente tem uma boa divulgação (ASSOCIAÇÃO, PESQUISA DIRETA, 2016).

Apesar de existir uma forte divulgação, observa-se que não há uma preocupação em informar os meios de hospedagem sobre o festival. Seria interessante uma parceria entre a organização do evento e os empreendimentos hoteleiros da região, uma vez que existem benefícios mútuos na execução do mesmo.

\footnotetext{
Muito mais que um acontecimento de sucesso, uma festa, uma linguagem de comunicação, uma atividade de relações públicas ou mesmo uma estratégia de marketing, o evento é a soma de esforços e ações planejadas com o objetivo de alcançar resultados definidos junto ao públicoalvo (BRITTO; FONTES 2002 p. 42).
}

O sexto questionamento buscou verificar se existem pacotes promocionais na pousada durante o evento, identificou-se que existem promoções no período, o que é algo positivo, como pode ser observado nas falas a seguir: "Pode ser feito sim, dependendo do número 
de pessoas, a gente pode fazer um pacote adequado. As pessoas que nos procuram merecem uma promoção, pois poderiam escolher outro empreendimento e escolheram o nosso" (MEIO DE HOSPEDAGEM, PESQUISA DIRETA, 2016).

Segundo Pinho (2001, p. 35) preço "é uma variável que pede a determinação de escolhas quanto à formação do preço final para o consumidor (alto, médio, baixo) e das políticas gerais a serem praticadas em termos de descontos, vendas a prazo, financiamento". Rebaixar os preços como forma de fazer com o cliente opte pelo meio de hospedagem é uma excelente estratégia para que ele vivencie os serviços do empreendimento e caso tenha suas necessidades atendidas, divulgue para amigos e familiares.

Kotler (2000) , afirma que "a promoção será a comunicação com o consumidor, ou seja, todo o esforço que irá motivá-lo ou encorajá-lo a comprar". Atualmente, a sociedade é movida por promoções, quanto melhor a relação custo e benefício, mais atrativa será a compra para o cliente.

\section{CONSIDERAÇÕES FINAIS}

O estudo teve como objetivo analisar os impactos que o Festival Quejaribe traz para a hotelaria de Jaguaribe, e de que forma o evento beneficia a economia local. Identificou-se que o evento contribui diretamente para o aumento da taxa de ocupação do meio de hospedagem estudado, e gera renda e empregos para a cidade.

$\mathrm{O}$ objetivo geral foi atingido, visto que o festival aumenta o fluxo de turistas na cidade, além das vendas no comércio local. Os objetivos específicos foram atingidos, pois a taxa de ocupação no período do evento tem uma grande elevação, chegando ao máximo, e nas outras épocas do ano a referida taxa é inferior.

As estratégias adotadas pelo meio de hospedagem são pacotes promocionais, que garantem a hospitalidade por um preço inferior. Além disso, o gestor apontou que o festival traz impactos positivos para a região e que a economia local é potencializada com tal evento.

A pergunta de partida foi respondida visto que o Festival do Queijo eleva a taxa de ocupação na hotelaria, durante o evento. Há a divulgação do queijo da região, beneficiando os produtores rurais, que potencializam vendas, assim como comerciantes e população.

Este estudo recomenda melhorias nas ações de marketing do evento, interação da Associação dos Produtores de Queijo com os meios de hospedagem, para que juntos possam desenvolver estratégias para benefícios mútuos. Recomenda-se ainda que outros eventos sejam desenvolvidos na região, já que estes elevam o número de visitantes na cidade.
A pesquisa aponta sugestões para futuros estudos, como: uma análise sobre a qualidade, pasteurização e o preparo do queijo coalho; as estratégias de planejamento da Associação dos Produtores de Leite para a realização do Queijaribe; eventos gastronômicos e seus impactos na economia local.

As empresas hoteleiras devem tomar medidas para que os eventos realizados na cidade sejam vistos como oportunidades de negócios, estando preparadas para receber os hóspedes. Já a Associação dos Produtores de Leite deve com o máximo de antecedência avisar os meios de hospedagem sobre a realização do evento, a fim de conseguir excelência na divulgação do evento.

\section{REFERÊNCIAS}

AITKEN, J. The role of events in the promotion of cities. Sydney: Conference paper, Events and Place Making, UTS, 2002.

ANSARAH, M. G. R.; NUNES, C. Hospitalidade nos serviços de alimentação como diferencial na prestação de serviços. In: Comunicação, Turismo e Hospitalidade. Santos: VII Encontro dos Núcleos de Pesquisa em Comunicação - NP, 2007.

AZEVEDO, G. A. A Gastronomia como Marca Identitária da Cultura Sanfranciscana. Salvador, 2010.

BAHL, M. Turismo e eventos. Curitiba: Protexto, 2004.

BARROCO, L. M. S. A importância da gastronomia como patrimônio cultural, no turismo baiano. 2008 . Disponível em: <http://econpapers.repec.org/article/ ervturdes/y_3a2008_3ai_3a2_3a6.htm> Acesso em: 27 mai. 2016.

BRAUNE, R.; FRANCO, S. O que é Gastronomia. São Paulo: Brasiliense, 2007.

BRITTO, J.; FONTES, N. Estratégias para eventos: uma ótica do marketing e do turismo. São Paulo: Aleph, 2002.

CAMPOS, R. F. F.; FERREIRA, J. F.; MANGUEIRA, M. N.; GONçALVES, M. C. R. Gastronomia nordestina: uma mistura de sabores brasileiros. In: XI Encontro de Iniciação à Docência. UFPB-PRG: Centro de Ciências da Saúde / Departamento de Nutrição / MONITORIA, 2002.

COBRA, M.; RANGEL, A. Serviços ao cliente: uma estratégia competitiva. 2. ed. São Paulo: Marcos Cobra, 1993. 
CORNER, D. M. R.; RODRIGUEZ, M. A gastronomia como atrativo no turismo cultural. Anais do IV Seminário de pesquisa em Turismo do Mercosul. Caxias do Sul, v. 7, n. 1, p. 1-33, 2006.

CRESWELL, J. W. W. Projeto de pesquisa: métodos qualitativo, quantitativo e misto. 2. ed. Porto Alegre: Bookman, 2010.

CUNHA, K. B.; OLIVEIRA, L. V. A gastronomia enquanto atrativo turístico-cultural. 2009.

Disponível em: <http://www.anapolis.go.gov.br/ revistaanapolisdigital/wp-content/uploads/2011/07/ A-GASTRONOMIA-ENQUANTO-ATRATIVO-HIST \% C3\%93RICO-CULTURAL1.pdf> Acesso em: 18 mar. 2018.

FAGLIARI, G. S. Turismo e Alimentação-Análises Introdutórias. 1. ed. São Paulo: Editora Roca, 2005.

GINANI, V. Índice de Aceitação de Preparações Regionais com Teor Lipídico Reduzido. Dissertação (Mestrado) - Universidade de Brasília, Brasília, 2005.

KOTLER, P. Administração de marketing. 1. ed. São Paulo: Prentice Hall, 2000.

LÁCTEA BRASIL. Queijo: Alimento nobre e saudável. 2006. Disponível em: <www.lacteabrasil. org.br>. Acesso em: 24 jun. 2016.

MITCHELL, R.; HALL, C. M. Consuming tourists: food tourism consumer behaviour, tourism around the world. Oxford, v. 2, n. 2, p. 60-80, 2003. Disponível em: <http://academia.edu/297671/Consuming Tourists_Food_Tourism_Consumer_Behaviour> Acesso em: 27 mai. 2016.

MONTANARI, M. Comida como cultura. 1. ed. São Paulo: Editora Senac, 2008.

OLIVEIRA, A. P. Turismo e Desenvolvimento:

Planejamento e Organização. 2. ed. São Paulo: Atlas, 2000 .

OLIVEIRA, S. La importancia de La Gastronomía en el Turismo Inn Compilación de Gastronomia. Buenos Aires, 2007.

PERRY, K. S. P. Queijos: aspectos químicos, bioquímicos e microbiológicos. Química Nova, SciELO Brasil, v. 27, n. 2, p. 293-300, 2004.

PINHO, J. B. Comunicação em marketing. 5. ed. Campinas: Papirus, 2001.

RICHARDS, G. Cultural tourism in Europe. 1. ed. Wallingford: CAB International, 1999.
SCHLUTER, R. G. Gastronomia e Turismo. São Paulo: Aleph, 2003.

SEGALA, L. V. Gastronomia e Turismo cultural. 2003. Revista Eletrônica de Turismo. Disponível em: <http://www.revistaturismo.com.br/materiasespeciais/ gastronomia.html> Acesso em: 27 mai. 2016.

SHIOZAWA, R. S. C. Qualidade no atendimento e tecnologia de informação. São Paulo: Atlas, 1993.

SIMON, F. Comer é um sentimento. 1. ed. São Paulo: Senac, 2006. Traduzido por: Eric Roland René Henault.

TENAN, I. P. S. Eventos. São Paulo: Eleph, 2002. 